\title{
ESCOLA PÚBLICA E EDUCAÇÃO NÃO-FORMAL CARACTERIZANDO O PROGRAMA PROJOVEM CAMPO
}

\author{
Luzia Nunes Mamoré ${ }^{1}$ \\ Paulo Gomes Lima ${ }^{2}$ \\ Antonio Bosco de Lima $^{3}$ \\ Glaucia Carvalho Gomes ${ }^{4}$
}

\section{RESUMO}

Em 2005, no bojo das ações afirmativas implementadas pelo governo Lula, foi criado o Programa Projovem Campo, cujo princípio norteador foi a da promoção de ações de educação para jovens do espaço rural entre 15 e 29 anos de idade. Neste artigo, propomonos a refletir sobre os limites e possibilidades transformadoras inscritas nesta política educacional voltada para o campo, situando-a no bojo da reflexão acerca da Educação Formal; Educação Pública e Educação Não Formal, cujo sentido norteador é contribuir para a promoção dos fundamentos de uma educação efetivamente democrática e emancipatória.

Palavras-chave: Educação Formal; Educação Não-Formal; Educação do Campo; Projovem Campo - Saberes da Terra; Inserção e oportunização social.

\section{PUBLIC SCHOOL AND NON-FORMAL EDUCATION: CHARACTERIZING THE PROGRAM "PROJOVEM CAMPO"}

\begin{abstract}
In 2005, in the midst of affirmative action implemented by the Lula government, was created the Program "Projovem Campo", whose guiding principle was the promotion of educational actions for young people in rural areas between 15 and 29 years old. In this article, we propose to reflect about the transforming limits and possibilities entered in this educational policy toward the field, standing in the midst of a reflection on the Formal Education; Public Education and Non-Formal Education, whose guiding meaning is contribute to the promotion of the fundamentals of an education effectively democratic and emancipatory.
\end{abstract}

Keywords: Formal Education;Non Formal Education;Education in the field; Projovem Field-Knowledge of the Earth; Social insertion and opportunity.

\section{Introdução}

A problematização central deste artigo enfatiza as proximidades entre as políticas de inserção do jovem ao que se convencionou chamar de mercado e a educação nãoformal.

O entendimento aqui presente acerca da inserção ao mercado - pois na lógica capitalista as políticas sociais têm um cunho focalizado, categorial e emergencial, na qual suas dimensões de recuperação, educação, oportunização e (re) enquadramento dos sujeitos deficitários de bens sociais - é o do que busca o enquadramento do sujeito no campo produtivo, ampliando a produção da mais valia.

Por sua vez, entendemos que a análise de projetos de educação voltados ao campo e ao rural podem subsidiar-nos no elucidamento de questões que envolvem a educação para 
além da que orienta pela inserção no mercado, se os mesmos favorecem uma perspectiva de educação popular ou de educação seletiva. Entende-se o modelo de educação seletiva que se enquadra na educação estatal, sendo esta criteriosa e objetivada. Já a educação popular, como educação pública, includente e democratizada, o que lhe confere, no limite, potencial democratizante. Em síntese, são estas questões anteriormente apontadas que compõem a introdução ao tema sobre o qual nos propomos a refletir.

Metodologicamente, partimos da conceituação da educação estatal e educação pública e, posteriormente, a concepção de educação não formal (como contraponto à educação formal). Como considerações finais, concluímos o artigo com a discussão acerca de uma política social educacional que objetiva a inserção do jovem do campo no mercado de trabalho: o Programa ProJovem Campo.

\section{Sobre Escola estatal e Escola pública}

A distinção conceitual entre escola estatal e escola pública tem causado certa celeuma no campo de investigação educacional. Alguns autores defendem que, por ser financiada pelo Estado, a escola é pública, já outros destacam que ela somente seria pública se tivesse uma auto-organização. Esclarecemos tais concepções e alguns autores desta tese mais adiante. De antemão, destacamos que uma terceira corrente surgiu com o advento da reforma do Estado a partir dos anos de 1995, cujo norteador é a ideia de público não-estatal, na qual uma organização privada pode prestar serviços públicos. Mas este não é objetivo deste artigo, embora se constitua em tema precioso e bastante rico pelas possibilidades que inscreve. Os fundamentos desta concepção podem ser encontrados no Plano Diretor da Reforma do Estado (BRASIL, 1995).

Estas são questões candentes sobre as quais a maior parte dos pesquisadores em educação tem se debruçado sobre as suas perspectivas e possibilidades. Que, de certo modo, atravessam nossas práticas, nossas necessidades e nossos dilemas. Não se trata, porém, de uma questão de cunho teórico. E, no intuito de desenvolvê-las situamo-las no campo sociológico e político, sob a perspectiva analítica do Liberalismo e Materialismo Histórico Dialético (MHD).

Conforme já afirmamos, trata-se de questões relevantes, provocativas e complexas, visto que as mesmas influenciam diretamente na nossa vontade/necessidade e nas nossas práticas, pois representam uma razão de ser do sujeito e de seu objeto. Não se trata desta maneira, de questões isoladas de nossas necessidades, posto que não estão dissociadas do mundo real, ou seja, das possibilidades e limites do aparelho escolar.

As nossas ações e concepções estão impregnadas por correntes que buscam explicar as relações sociais, a função do Estado e as atividades humanas, o que amplia a complexidade que já envolve a questão, posto que se trata, no caso da educação formal, de distinguir correntes que influenciam na Organização do Trabalho Escolar (OTE).

No campo do Liberalismo a escola serve para alguma coisa (ou para muito), adequar os sujeitos à sociedade em movimento, ao mundo que se transforma. Como podemos ver, nesta vertente econômico-ideológica, não são os sujeitos que transformam o mundo, mas são estes que se adéquam a ele e devem atender às demandas por ele colocadas. A escola, neste sentido, tem uma função instrumental de moralizar os indivíduos e capacitá-los, educando suas potencialidades, suas habilidades para adequá-los a um modelo de sociedade que prescinde dos indivíduos enquanto sujeitos individualizados e passivos. Assim, a potencialidade está nos sujeitos e não na coletividade, está nos sujeitos "classificados", . Como exemplo de formuladores e defensores desta centralidade no podemos citar Adam Smith (1993) e em Jacques Delors (1995). 
No campo do MHD temos duas concepções: aqueles que referenciam que se a escola reproduz socialmente e culturalmente, portanto educacionalmente, as relações estabelecidas em sociedade, ela também pode ser um campo de produções. Para tanto, ela deve ter manutenção estabelecida pelo Estado. Trata-se, então, de uma escola estatal que, possivelmente, poderia responder por um modelo de educação formador de mentalidades critica e cidadã. Neste campo temos educadores como Vitor Paro (2001), José Libâneo (2004), dentre outros.

Uma segunda concepção diz respeito àqueles que defendem a escola pública, ou seja, ela tem que ser "organizada" pelo povo. Seu campo decisório e de trabalho é centrado nas decisões coletivas. Portanto, mesmo que ela seja mantida pelo Estado ela será dirigida por uma concepção popular. Daí entender a escola como escola popular, ou educação popular. Neste campo estão signatários de teses libertadoras e libertárias, como a de Bruno $^{6}(2002$, p. 38), para quem

É na autoorganização dos envolvidos no processo de educação das novas gerações da classe trabalhadora, pais, alunos e professores, que, criando seus próprios espaços públicos onde os interesses são debatidos naquilo que tem de comum e na diversidade em que se apresentam, que se poderá chegar à formulação de alternativas reais às hierarquias de comando do poder que nos é imposto, esteja este configurado na sua forma convencional ou em rede, como se gosta tanto hoje de apresentá-lo.

Encontramos, também, os princípios de emancipação e de educação popular na prática educativa do MST

\section{I - Princípios filosóficos e pedagógicos}

No Cadernos de Educação $n^{\circ} 8$ temos os Princípios de Educação do MST. Aqui passaremos apenas a citá-los. Vejamos:

\section{a) Princípios filosóficos}

1) Educação para a transformação social.

2) Educação para o trabalho e a cooperação.

3) Educação voltada para as várias dimensões da pessoa humana.

4) Educação com/para valores humanistas e socialistas.

5) Educação como um processo permanente de formação e transformação humana.

\section{b) Princípios pedagógicos}

1) Relação entre teoria e prática.

2) Combinação metodológica entre processos de ensino e de capacitação.

3) A realidade como base da produção do conhecimento.

4) Conteúdos formativos socialmente úteis.

5) Educação para o trabalho e pelo trabalho.

6) Vínculo orgânico entre processos educativos e processos políticos.

7) Vínculo orgânico entre processos educativos e processos econômicos.

8) Vínculo orgânico entre educação e cultura.

9) Gestão democrática.

10)Autoorganização dos estudantes e das estudantes. (Grifos do autor). (MST, 2004).

Além dos escritos de autores da vertente marxista, como Lombardi que destaca que

Marx e Engels não duvidavam de que era necessário às instituições públicas se responsabilizarem pela educação. Eles repudiavam o controle 
que o Estado exercia sobre ela, já que esse repúdio era a forma de impedir que a burguesia contasse, além dos outros poderes de que já dispunha, com toda estrutura escolar posta a seu serviço. (LOMBARDI, 2011, P. 228).

Certamente, é relevante destacar os princípios educativos de formação do homem presentes na nossa sociedade (que é a sociedade real, da qual falamos e na qual vivemos). Este princípio encontra-se, por exemplo, em documento da Secretaria de Ensino Fundamental do Ministério da Educação (MEC), e que vigora até o presente tempo. Divulgado a partir de 1997, o Documento Introdutório dos Parâmetros Curriculares Nacionais (PCNs) referenciam que

\section{Princípios e fundamentos dos Parâmetros Curriculares Nacionais \\ $\mathrm{Na}$ sociedade democrática, ao contrário do que ocorre nos regimes autoritários, o processo educacional não pode ser instrumento para a imposição, por parte do governo, de um projeto de sociedade e de nação. Tal projeto deve resultar do próprio processo democrático, nas suas dimensões mais amplas, envolvendo a contraposição de diferentes interesses e a negociação política necessária para encontrar soluções para os conflitos sociais. (Grifos do autor). (Brasil, 1997, p. 33).}

Este é o primeiro parágrafo, portanto, a tese central, ou o espírito dos princípios focados nos PCNs. O que notamos? Que ele tem uma proposição realmente diferenciada, e democrática, entretanto: a) os próprios PCNs foram impostos, conforme mostram dezenas de estudos sobre o mesmo ${ }^{7}$ e, b) de qual democracia os PCNs tratam, participativa ou representativa? Popular ou Liberal?

Não bastasse isto o texto é meramente prescritivo. Se o projeto é resultado de uma negociação, tal negociação deve ter uma organização democrática, participativa, transparente. Não é o que temos visto no decorrer da implementação de políticas nas últimas décadas (1990, 2000, 2010), onde a participação (a negociação) política focalizou, ora lobbies poderosos, ora audiências públicas.

[...]

Fizemos esta introdução para subsidiar a vertente defendida no decorrer deste artigo. Fazendo uma distinção entre escola estatal e escola pública, focando a escola pública como o local possível de construção do campo da democracia-participativa, da problematização da cidadania e da construção de um modelo de sociedade que supere a divisão social do trabalho, concorrendo para a emancipação da sociedade e do ser humano.

Feita tal introdução, adentremos à concepção de educação não-formal, compreendendo que a mesma se aproxima da concepção de escola pública, popular, cujos alicerces educativos se constituem em prática de democracia-participativa.

\section{Sobre Educação Não-Formal}

Segundo Gohn (2001), a Educação Não-Formal foi caracterizada durante os anos setenta como uma atividade fora do marco de referência do sistema formal de educação, destinada a subgrupos da população, principalmente adultos e crianças. No Brasil, deste período e da década posterior, a Educação Não-Formal não esteve presente nos grandes embates e debates, nem entre os educadores, tampouco nas políticas públicas.

O destaque que ganha a Educação Não-Formal ocorreu na década de noventa, devido à reestruturação do Estado e as conseqüentes mudanças de enfoque nas políticas sociais que, se já eram focalizadas, setoriais e categoriais, passaram a ser mais ainda 
subtraídas, jogando para a sociedade a responsabilidade, através de projetos de parcerias para a solução dos problemas da comunidade.

A lógica presente no contexto dos anos noventa é a de que a crise do sistema capitalista levou a uma crise dos sistemas educativos. Tal crise é simplificada no argumento de que se trata de uma crise, pela má gestão de recursos, ou seja, o serviço público é identificado como produtor de serviços de má qualidade. Tal caracterização é construída para esvaziar o poder público enquanto ente mantenedor dos serviços sociais.

A crise na educação leva-a a remodelar, redefinir o seu papel, a subordinar-se às novas configurações do mundo produtivo. Tal reconfiguração provoca um esvaziamento do sistema educacional formal, devido às novas necessidades do mercado. Não se requer mais sujeitos que tenham a apreensão de conhecimentos, mas sujeitos que tenham competências e habilidades para a sobrevivência, diante da remodelação do mercado de trabalho, voltado agora para a chamada empregabilidade. Concepção que, no limite, dissocia o trabalho do contexto contraditório e complexo que envolve uma "sociedade do trabalho" em uma crise de reprodução estrutural e responsabiliza o sujeito pela sua condição de inserção. Assim, inserir-se no mercado de trabalho é reduzida à premissa de que se o indivíduo é ou não competente, individualizando a questão, conformando a idéia de uma suposta "sociedade de indivíduos".

Tais "conhecimentos", que não são adquiridos basicamente na escola, apontam para que o projeto anterior de "formação para o trabalho", "reparação para o trabalho", "formação para a cidadania", perdeu centralidade. A formação agora é para a vida, o que extrapola o âmbito da escola formal. O indivíduo pode compor sua educação nos meios comunitários, no sindicato, nas associações de bairro, nas ONGs, dentre outras organizações do terceiro setor.

A formação do indivíduo e seu acesso ao conhecimento são muito bem explicitados no texto de Delors (2001). Para o autor o indivíduo não interage nem modifica o mundo, ao contrário adapta-se ao mundo (p. 89). Não se aprende somente na escola, e o aprender significa obter informações (Aprender a conhecer). Aprender a fazer significa aprender a se adequar à sobrevivência do trabalho assalariado ou do trabalho informal, ou seja adaptar-se ao meio (p. 95). Outro pilar é o Aprender a viver juntos, que significa ser tolerante com os antagonismos, ou seja, viver o melhor possível numa sociedade fundada pela divisão do trabalho (p. 99). E, finalmente, o quarto pilar, Aprender a ser, significa se adaptar ao mundo da competitividade. A educação, portanto, é um tesouro a ser descoberto, e que está dentro de cada um de nós.

Nesta perspectiva, a educação formal não teria condições de responder às necessidades postas no mercado, lidar com o tempo e espaço, cada vez mais restritos, cada vez mais cibernéticos, cada vez mais tecnologizados. Novos modelos educacionais, no qual se insere a Educação Não-Formal, a Educação Informal e a Educação a Distância, responderiam melhor as necessidades da sociedade.

A compreensão do projeto educativo como obra exclusiva da escola formal perde "status". Os conteúdos formalizados perdem sua dimensão num mundo onde a informação é dinâmica e virtual. Onde os conhecimentos são construídos de forma que a escola formal não consegue acompanhar. Daí, disciplinas como filosofia e sociologia perderem espaço no currículo tradicional. A conseqüência é que outras disciplinas também perdem espaços para os intitulados projetos disciplinares.

Ou seja, exige-se das pessoas novas habilidades, entre elas a de gestão. Não importa mais possuir um grande acervo de conhecimentos, mas sim o domínio de certas habilidades básicas, tais como comunicar-se (de preferência em mais de uma língua), domínio da linguagem das máquinas 
e, sobretudo habilidade de gestão (de gerir sua própria vida e carreira, equipes, conflitos, etc). (GOHN, 2001, p. 95).

A comunidade, neste contexto, é conclamada por vários projetos para prestarem serviços voluntários à escola. Para contribuírem na execução de projetos. Danças, música, teatro, costura, capoeira, vão se constituindo em projetos que vão se alargando e tornando a razão de ser da escola. Por sua vez, estes projetos passam a ocupar o tempo e espaço da escola, tornando-se desta a nova preocupação e em torno e em função da qual passa a se movimentar. Ocorre, assim, o esvaziamento do o conhecimento formal.

A escola usa seu tempo e espaço para elaborar projetos, que muitas vezes não tem relação com disciplinas específicas. O espaço escolar, que já há muito estava se transformando em refeitório, creche, consultório médico e oftalmológico, consultório veterinário, progressivamente, também assume o papel de local de lazer da comunidade. Destaca-se que a questão aqui presente não é da pertinência ou não destes outros equipamentos ou serviços, mas sim do modo como estes supostos papéis da escola minam sua condição no que se refere à sua função social primordial.

Note-se que não haveria problema algum se tal movimento de papel e função da escola fosse acompanhado por um projeto de educação, ou se tais projetos embasassem-se histórica, filosófica e socialmente um projeto de educação, um projeto pedagógico articulado. Porém, tais projetos, em geral, tem esvaziado aquilo que a escola já tinha dificuldades em concretizar: alfabetizar e socializar o conhecimento, concomitante à atomização e fragmentação do projeto escolar: não raro, são ações propostas externamente e por sujeitos também externos à escola e ao território em que está inserido.

É neste contexto que aparecem e se ampliam as "políticas" de assistencialismo, voluntarialismo e associativismo. Aparecem os amigos da escola, da informática, da manutenção, da alfabetização... Enfim, aqueles que estão nos termos que definem estar sem que esta definição seja norteada coletiva e democraticamente pelo conjunto de sujeitos que integram a escola e constroem o seu projeto político e pedagógico. Se considerarmos que a escola é constituída de relações sociais e culturais e que esta é um espaço de produção cultural que está contida na relação pedagógica de constituir bases de conhecimento para a superação da ignorância e do senso comum, esta construção tem que ser coletiva. Mais que isso, tem que ser norteadora das ações que se desenvolvem neste espaço. Na medida em que estes projetos chegam fragmentariamente, todo este processo fica comprometido.

Já a Educação Não-Formal possui uma característica essencial, que atrai e contribui para a relação ensino-aprendizagem, que é a possibilidade de utilizar espaços e tempos não convencionais para a aprendizagem, o que torna a relação educativa diferente da ocorrida no espaço convencional de formação. Diríamos, realiza-se a aquisição de conhecimentos de forma "criativa".

Porém, ao mesmo tempo em que este aspecto é importante, é necessário lembrar que adquirir conhecimentos está relacionado com disciplina, com rigor científico, o que vai além da formação de opiniões, é constituir elementos eruditos para sustentar opiniões. E isto, em geral, não se aprende com "prazer exacerbado", daí a "chatice" da escola formal.

Distinguem-se, desta forma, várias educações (formal, informal e não-formal). Caracterizar o objeto de uma e de outra pode contribuir para construir elementos que possibilitem uma unidade entre elas, segundo Gohn

O que diferencia a educação não-formal da informal é que na primeira existe a intencionalidade de dados sujeitos em criar ou buscar determinadas qualidade e/ou objetos. A educação informal decorre de 
processos espontâneos ou naturais, ainda que seja carregada de valores e representações, como é o caso da educação familiar. (2001, p.100).

A Educação Formal é, portanto, fundada numa política de Estado, se constitui em política educacional, com critérios, objetividade e seletividade. Constitui uma necessidade política e social de formar indivíduos para uma dada sociedade.

Tal organização requer investimento, planejamento, ou seja, o uso de uma racionalidade que objetiva a conservação de valores ou a transformação de valores.

A Educação Não-Formal é contida por atividades informais, esporádicas, pontuais, categoriais. Não se universaliza, tem a sua razão limitada, dentro do tempo e espaço da sociedade.

Portanto, a existência da Educação Não-Formal é incontestável e necessária. Porém não deve se tornar uma política de substituição da educação de caráter formal, o que parece vir ocorrendo. Afinal, não é uma disputa por empregos ou pelo espaço da escola, é uma disputa de concepção de educação e de Estado, de projetos políticos que caracterizam o Estado como responsável prioritário pela educação (como aparece na Constituição Federal, Artigo 205) ou a sociedade e a família como tal (como aparece na LDB 9.394/96, Artigo $\left.2^{\circ}\right)$.

Outro aspecto importante presente nas experiências de Educação Não-Formal, mesmo que sofra críticas, é que garante a participação de um contingente mais amplo da comunidade, o que pode sugerir a participação destas pessoas em atividades além daqueles de seu cotidiano, o que pode sugerir, portanto, organização política, visto que no espaço tradicional da educação escolar formal, o debate público tem se restringido aos canais legítimos de participação da comunidade: Conselhos e APMs.

Tais indicativos sugerem que modelos de escola estatal se sustentam por uma lógica de organização formal, cuja fundamentação tem referência na democracia formal, representativa, indireta. As experiência de educação não-formal (e também a informal) sugerem um modelo de organização do trabalho escolar coligado a uma lógica da democracia direta, participativa.

A educação do campo tem uma áurea de popular. Ou seja, de condições voltadas para uma modelo de organização, a princípio pública, no sentido republicano de democrático, de participativo. Veremos a seguir uma experiência a partir de um projeto de educação voltado para o campo.

\section{A formalidade da educação do campo: o Programa ProJovem Campo}

A inserção e oportunização social do homem no campo constituíram-se como um dos grandes desafios do governo brasileiro na primeira década do século XXI. Articuladas a esse quadro, questões como justiça social, eliminação da pobreza, fortalecimento das condições de vida de comunidades socialmente excluídas, dentre outros, constituíram-se como eixos para a elaboração de políticas públicas para o atendimento das demandas identificadas.

As políticas públicas constituem-se como ações do Estado destinadas a atender as solicitações sociais que em maior ou menor medida necessitarão de agentes normativos para ocumprimento do direito cidadão. Elas não são construções abstratas advindas de um único segmento ideológico, visto que existem contextos conflitivos que não podem ser ignorados numa sociedade democrática.

Ao identificar a situação do homem do campo, quanto a sua formação profissional e pessoal em nível acadêmico no referido período, à luz das políticas públicas, inúmeras ações ${ }^{8}$ foram elaboradas com o intuito de encaminhar a questão, dentre elas, os "Saberes da Terra" que em 2005, foi incorporada ao Programa Nacional de Inclusão de Jovens 
(Projovem), caracterizando-se como uma de suas modalidades, que numa projeção específica se expressava em oferecer "[...] qualificação profissional e escolarização aos jovens agricultores familiares de 18 a 29 anos que não concluíram o ensino fundamental" (BRASIL, 2011), como maneira de identificar a ação, a sua denominação específica passara a ser cunhada como ProJovem Campo - Saberes da Terra. O objetivo desse programa era o de ampliar o acesso e a qualidade da educação "[...] respeitando as características, necessidades e pluralidade de gênero, étnico-racial, cultural, geracional, política, econômica, territorial e produtivas dos povos do campo". (BRASIL, 2011).

As políticas públicas definiram Educação do Campo como um espaço educacional com objetivo de atribuir visibilidade aos camponeses com enfoque maior no trabalho, enquanto gerador das condições necessárias para de produção para subsistência. Tal apropriação e uso de direitos é resultado de anos de luta dos movimentos sociais que denunciavam e denunciam historicamente os descasos da realidade brasileira quanto à divisão social de classes e, mais especificamente, das particularidades específicas do homem do campo que, marginalizado não é praticamente expropriado e geralmente se evadia da zona rural.

Esse quadro não passara despercebido tanto na Constituição de 1988, quando da proposta de favorecer a radicação do homem do campo por meio de algumas políticas indutoras, assim comona Lei de Diretrizes e Bases da Educação Nacional n 9.394/96 (LDB).

A LDB mencionada, reforçando os princípios de apoio e garantias de direitos do homem da zona rural ou mais comumente chamado de homem do camporeconhece em seus art. $3^{\circ}$, dentre outros princípios da educação nacional, o constante no inciso XI que prevê a "[...] vinculação entre a educação escolar, o trabalho e as práticas sociais" (BRASIL, 1996). O imperativo desse princípio embora abranja a educação como um todo no Brasil, para a educação rural tem um sentido implícito que não dissocia escola e aplicação dos conhecimentos produzidos nesse para um projeto maior de oportunização, inserção social a partir da realidade vivenciada, sendo essa uma das principais demandas da agricultura familiar.

Quanto ao imperativo de garantir que o homem do campo fosse penalizado pelo sistema educacional, por conta dos seus tempos, currículos e espaços determinados para educação escolar formal, a LDB 9.394/96, previu e possibilitou a organização da educação básica levando em conta as peculiaridades dos processos de aprendizagem e condiçõesda região onde as demandas sociais por educação ocorrerem, como segue:

Art. 23. A educação básica poderá organizar-se em séries anuais, períodos semestrais, ciclos, alternância regular de períodos de estudos, grupos não-seriados, com base na idade, na competência e em outros critérios, ou por forma diversa de organização, sempre que o interesse do processo de aprendizagem assim o recomendar.

$\S 1^{\circ}$ A escola poderá reclassificar os alunos, inclusive quando se tratar de transferências entre estabelecimentos situados no País e no exterior, tendo como base as normas curriculares gerais.

$\S 2^{\circ} \mathrm{O}$ calendário escolar deverá adequar-se às peculiaridades locais, inclusive climáticas e econômicas, a critério do respectivo sistema de ensino, sem com isso reduzir o número de horas letivas previsto nesta Lei. (BRASIL, 1996, sublinhado nosso).

A complementação da idéia de que as diversidades sócio-culturais e econômicas não deveriam ser desprezadas na organização e efetivação da escola no campo foramcontempladas em forma de artigo específico, recortando a nova orientação que 
deveria ser dada para a educação rural. Nesse sentido, concordamos que houve a contemplação dessa preocupação, como segue:

Art. 28. Na oferta de educação básica para a população rural, os sistemas de ensino promoverão as adaptações necessárias à sua adequação às peculiaridades da vida rural e de cada região, especialmente:

I - conteúdos curriculares e metodologias apropriadas às reais necessidades e interesses dos alunos da zona rural;

II - organização escolar própria, incluindo adequação do calendário escolar às fases do ciclo agrícola e às condições climáticas;

III - adequação à natureza do trabalho na zona rural. (BRASIL, 1996, sublinhado nosso).

Essa nova configuração da Educação Nacional contribuiu para que a Educação do Campo se efetivasse através da legislação brasileira, outro traço de reconhecimento dos direitos sociais destacados, a projeção do Programa de Educação do Campo Projovem Campo - Saberes da Terra.

As políticas publicas ${ }^{9}$ foram organizadas em forma de leis na tentativa de minimizara falta de diretrizes operacionais específicas destinadas aos residentes do campo. O Programa de Educação do Campo Projovem Campo - Saberes da Terra é, portanto, parte das políticas de inclusão social que, inaugurado em $2005^{10}$, deveria priorizar a sociabilidade e profissionalização como parte técnica acerca da produção, a adequação do currículo e tempo de estudo para respeitar as especificidades do campo, não a sua conformação aos dispositivos previstos para a educação formal que se pratica nas escolas de zona urbana. A grande ênfase do Programa centra-se na concepção de uma educação a partir do campo e para o campo na perspectiva de atribuir à educação oferecida algo além duma escola urbana no meio do mato.

É substancial destacarmos que para a interiorização ou "inculcação" da compreensão de que diferentes populações requerem condições específicas de atendimento necessário se faz a desconstrução de paradigmas pré-concebidos quanto a homogeneização das populações, uma vez que coloca à parte, leituras necessárias que são delimitadas por uma realidade sócio-cultural e econômica específica. Essas últimas são importantíssimas no que diz respeito a existência de tempos e modos diferentes de ser, viver e produzir, consequentemente se constitui a necessidade de Escolas do Campo.

Com o objetivo histórico de serem contempladas tais considerações as políticas públicas para a educação do homem do campo, entre o final da década de 1990 e com mais ênfase na primeira década do século XXI (como o Programa de Educação do Campo ProJovem Campo - Saberes da Terra), passaram dentre outras iniciativas, a promover ênfase na educação para desenvolvimento da Agricultura Familiar e Sustentabilidade. Tais iniciativas visavam além de conter o fluxo migratório campo-cidade, também a chamar a atenção necessária ao homem do campo, historicamente secundarizada pela desvalorização de seu trabalho. A esse respeito Caldart (2002, p. 27) destaca que:

A educação do campo se identifica pelos seus sujeitos. É preciso compreender que,por trás da indicação geográfica e da frieza de dados estatísticos esta uma parte do povo brasileiro que vive neste lugar e desde as relações sociais especificas que, compõem a vida no e do campo, em sua identidade comum; estão pessoas de diferentes idades, estão famílias, comunidades, organizações, movimentos sociais [...] A perspectiva da educação do campo é exatamente a de educar este povo, estas pessoas 
que trabalham no campo, para que se articulem se organizem e assumam a condição de sujeitos de direção de seus destinos.

O Programa de Educação do Campo Projovem Campo - Saberes da Terra, criado durante a primeira gestão do governo Lula da Silva estava fundamentado num eixo articulador - Agricultura Familiar e Sustentabilidade - que seria a matriz orientadora de eixos temáticos para o trabalho com os estudantes do campo. Tendo como população alvo a formação de jovens agricultores entre 15 e 29 anos e sua instrumentalização para o trabalho os eixos temáticos foram organizados em número de cinco: a) Agricultura familiar: identidade, cultura, gênero e etnia; b) Sistemas de produção e processos de trabalho no campo; c) Cidadania, organização social e políticas públicas; d) Economia Solidária ee) Desenvolvimento Sustentável e Solidário com enfoque Territorial.

No desenvolvimento desses eixos deveriam ser contempladas a formação profissional e a escolarização pertinente, cuja organização da proposta curricular deveria prever dois tempos a) um momento para agregação dos conhecimentos na escola (saberes elementares, técnico-científicos, planejamento, possibilitação de pesquisas, organização de atividades em grupos, confecção de materiais pedagógicos, etc) - Tempo Escola e b) outro período para que os jovens se dedicassem a socialização dos aprendizados em sua comunidade: as pesquisas, os estudos, os experimentos, inclusive tentando identificar pontos que favorecem ou dificultam o desenvolvimento das atividades voltadas para a Agricultura e Sustentabilidade de cada local de moradia - Tempo Comunidade.

Sabemos e reconhecemos que existem algumas solicitações sociais sendo contempladas em tal iniciativa, entretanto, não se pode deixar de considerar que se trata de uma política de governo, cuja natureza ou grau de intervenção é conjuntural ou emergencial, isto é, identificadas algumas situações de demandas ou vulnerabilidades de alguns grupos sociais, ações pontuadas são canalizadas para o seu encaminhamento. Os possíveis benefícios têm abrangência segmental e fragmentada, pois se configuram em política social categorial e focal, não tendo uma abrangência nacional, são nichos identificados e privilegiados pelo zelo governamental (o que pode incidir em patrimonialismo, coronelismo e/ou clientelismo).

Enquanto no Brasil não forem inauguradas políticas de Estado de cunho universalista que, de fato, promovam a democratização e acesso aos benefícios sociais, quaisquer outras iniciativas precisam ser muito bem consideradas, visto que numa dada sociedade com demarcadas dimensões de divisões de classe social, as políticas compensatórias induzem à idéia do direito e da justiça social, velando em sua estrutura o seu oposto.

Entendemos que o Programa de Educação do Campo ProJovem Campo - Saberes da Terra deve ser entendido sem perder de vista os pontos contraditórios de sua própria intenção pública, o seu tempo de duração e sua efetividade, uma vez que a passagem de uma política de governo para uma política de estado é compassada por sua validação e solicitações de segmentos sociais que primem pela universalização do direito. A agricultura familiar e a sustentabilidade é um dos pontos de um todo maior que passa por essa discussão, daí a necessidade de aprofundarmos os seus fundamentos e algumas condições específicas que, enquanto políticas compensatórias, se dão de maneira insuficiente mesmo para os espaços recortados aos quais se destina.

A legislação brasileira, como destacado anteriormente, garante educação específica para a população residente no campo com direitos sociais e formação integral dos sujeitos. Entretanto, em nível de ensino fundamental, portanto com um teor de política compensatória, para proporcionar acesso à escolarização àqueles que não a tiveram em idade apropriada O Programa ProJovem Campo (BRASIL, 09, s/p) 
[...] se destina a desenvolver uma política que fortaleça e amplie o acesso e a permanência de jovens agricultores (as) familiares, situados na faixa etária de 18 a 29 anos, no sistema formal de ensino. Tem como finalidade proporcionar formação integral ao jovem do campo por meio de elevação de escolaridade, tendo em vista a conclusão do Ensino Fundamental com qualificação social e profissional [...].

O programa do governo federal faz parte da política nacional direcionada a jovens agricultores familiares considerados conforme os requisitos do art. $3 \circ$ da Lei n॰ 11.326. de 24 de julho de 2006, mas ainda é objeto de discussão na transição ente política de governo e política de estado, entre políticas de abrangência segmentada e políticas de alcance universal tanto quanto à democratização, quanto ao acesso e extensão. A Educação de Jovens e Adultos neste modelo integra a Qualificação Social e Profissionaldestinada Agricultores(as) Familiares com o objetivo de desencadear ações coletivas na possibilidade de maior atendimento à solicitações do homem do campo.

A linha diretriz do currículo para a educação do homem do campo que integra e alterna tempos e espaços formativos certamente é uma proposta diferenciada sobre a realidade de uma segmento populacional historicamente marginalizado, portanto, a valorização do meio, sem deixar de lado as apropriações dos conhecimentos culturalmente construídos são contemplados em maior ou menor grau no Programa, daí a sua atualidade e necessidade de se constituir numa parte consolidada da política de estado para esse contexto.

A organização curricular prevê a intervenção pedagógica centrada no diálogo constante com a realidade vivida, isto é, na interação dos sujeitos a com a comunidade e trabalho, desencadeando questões que articulam os conteúdos a partir de realidade prática dos educandos (as), reforçando o que o Plano Nacional de Qualificação 2003-2007 (BRASIL, 2003, p.30) orienta quanto a uma educação integral do/da trabalhador/a que requer "[...] uma construção curricular que envolva as dimensões: técnico-científica, sociopolítica, metodológica e ético-cultural" para garantir formação integral sendo necessário visualizar saberes do conhecimento popular nas práticas de qualificação social e profissional apropriadas dastecnologias e conceitos reunidos pelas áreas do conhecimento. Nessa linha direcional, o Programa se propõe a garantir e aprimorar os sentidos identificados na realidade do homem do campo, tarefa em construção, de suas reivindicações sobre os fazeres da e na terra. Entretanto, outras questões ainda são muito compartimentalizadas nas discussões e encaminhamentos, como é o caso da propriedade rural.

É, ainda, oportuno destacar que o Projeto Político Pedagógico do Projovem Campo Saberes da Terra (BRASIL, 2008) explicita a necessidade da ação dos sujeitos em construção coletiva trabalhadas em períodos dialógicos de a sob a forma de alternância regular direcionado a ressignificação da população que vive no campo e do campo onde cria e reproduz além das relações sociais.

São previstos dois anos de aprendizados e troca de experiências, composto por períodos de alternância em tempos de estudos e pesquisas a partir das ocupações que compõem o eixo temático articulador. O eixo temático articulador Agricultura Familiar e Sustentabilidade é composto por cinco ocupações (Sistema de Cultivo, Sistema de Criação, Extrativismo, Aqüicultura e Agroindústria) do Arco ocupacional Produção Rural Familiar para ajudar compreender melhor os problemas do camponês nas suas relações sociais no espaço do bem viver objeto da análise deste artigo. O momento oportuno para dinamizar formas e intervenção social a partir da realidade local. (BRASIL, 2008, p.16) 
Ora, no estado capitalista as políticas sociais têm se caracterizado como programas emergenciais e categoriais, pouco afeitos ao caráter universalizante. Mas esta caracterização não pode causar imobilismo quanto à possibilidade de interferências, ingerências e resistência a elas. A infidelidade na implementação pode traçar outros caminhos para um modelo com nuances de centralidade e burocracia.

Embora o ProJovem-Campo: Saberes da Terra tenha como proposta a qualificação profissional e escolarização aos jovens agricultores existem questões de fundo que ainda necessitam ser resolvidas: o direito à terra, a estrutura de programas de geração de renda, $o$ apoio e criação de instrumentos para a fixação do homem no campo. Nesse sentido, o ProJovem, como outras políticas sociais afirmativas, sinaliza que a inserção e oportunização social desencadedas pelo programa é válida, mas muito frágil.

\section{Considerações finais: formação e sujeito (necessário) para a educação popular}

Construir outra escola é fundamental, faz parte da utopia de viver em uma outra sociedade, sem miséria, sem fome, sem educação desigual, sem justiça desequilibrada, sem polícia ostensiva, sem trabalho infantil, sem trabalho escravo.

Que escola e que professor teremos/formaremos para tal educação? Claro que são os germes por nós (im)plantados, pois, somente com mudanças radicais da sociedade poderemos avançar no sentido de uma "educação que, superando a divisão entre trabalho manual e intelectual, entre saber e fazer, entre trabalho, instrução e ginástica, volte-se para a formação integral do homem." (LOMBARDI, 2011, p. 158).

Quanto à formação do educador e sua ação torna-se necessário que o pedagogo/docente compreenda o seu campo de atuação e como este se organiza (administrativamente e pedagogicamente), mas tenha, para, além disto, a compreensão sobre as políticas públicas educacionais. Assim, ocorrerá uma possibilidade de diferenciar projetos, programas e políticas de governo. Afinal, se é determinado governo que implanta políticas quem as implementa somos nós, os trabalhadores da educação.

A pergunta central que se coloca é se a escola pode alguma coisa. Se ela tem poderes para transformar a sociedade. A resposta que se apresenta, em princípio é simples: sim, ela pode! Pode, por ser ela transmissora de conhecimentos e reprodutora das relações sociais, determinantes da sociedade, condicionadas pela organização do trabalho no modo de produção capitalista. Mas, a escola não pode somente reproduzir, ela pode (e deve) produzir algo. Depende como se subordinam seus trabalhadores, se se colocam como trabalhadores "classificados", nos dizeres de Taylor (1995), ou se concorrem a favor do campo da libertação e da emancipação popular. Tratam-se os conteúdos como elementos que são superiores a construção educativa dos valores ou condutas ou se fazem da escola um campo onde, os saberes são importantes, mas a relação democrática na organização do trabalho é mais importante para a condução cidadã.

$[\ldots]$

É preciso que a escola seja o centro das atenções, mas, que ela não esteja isolada, seja tocada/manifestada pelas instituições várias que estão no seu entorno ou que façam referência a ela.

Que a iniciativa seja multilateral, que a dimensão da escola ultrapasse seu limite didático-conteúdista e se configure como escola popular, integral e interdisciplinar.

O espaço de formação da educação formal e da Educação não-formal não são antagônicos, são diferentes. E é necessário que os educadores tenham compreensão disto, pois podem construir um projeto que articule Educação Formal e Não-Formal. Podem romper este falso antagonismo e aprimorar a qualidade social da educação formal. Para isto 
não precisamos de profissionais aventureiros, ou bombeiros, mas profissionais que compreendam a dinâmica da realidade social, que domine os conteúdos de seu trabalho e que tenha compromisso políticos.

As atividades não formais que ocorrem no cotidiano da escola devem ter uma articulação com os conteúdos sistematizados. Bem como a escola, através de suas instituições auxiliares (Conselho e APM) podem desenvolver um projeto político discutindo com a comunidade sobre as práticas de tais atividades. Neste rol entram a campanha de vacinação, a campanha contra pediculose, o bolsafamília, etc.

Trata-se de uma construção histórica que envolve sujeitos coletivos, amplas manifestações, na qual "os resultados isolados estão longe de ser suficientes. É preciso que a concepção da educação social penetre nas amplas massas, assim como em todas as organizações sociais eem todas as instituições estatais." (PISTRAK, 2003, p. 57).

Educar é correr riscos, envolver-se nas culturas populares significa contrair vírus populares, saberes populares, conhecimentos populares. Então, precisamos sim, "nos arriscar em discussões e reflexões que apontem um norte para esse momento tão conflituoso por qual passa a sociedade e consequentemente a educação." (PENTEADO et. al., 2012).

A luz do capital ofusca a utopia socializante. Mas, como se estivéssemos em uma caverna, na penumbra, a luz de um sonho faz alguma diferença ou como diz Thiago de Mello - "Faz escuro mas eu canto"

Faz escuro, mas eu canto por que(a)manhã

vai chegar.

Vem ver comigo companheiro, vai ser lindo, a cor do

mundo mudar.

Vale a pena não dormir para esperar,

porque (a)manhã vai chegar.

\section{Referências}

BRASIL. Ministério da Educação e Cultura. ProJovem - Saberes da Terra. Disponível em http://portal.mec.gov.br/index.php?id=12306\&option=com_content\&view=article. Acesso em 12/07/2011.

PRESIDÊNCIA DA REPÚBLICA. CASA CIVIL. Lei $\mathbf{n}^{\mathbf{0}} \mathbf{1 1 . 3 2 6}$, de 24 de julho de 2006. Estabelece as diretrizes para a formulação da Política Nacional da Agricultura Familiar e Empreendimentos Familiares Rurais. Disponível em: http://www.planalto.gov.br/ccivil_03/_ato2004-2006/2006/lei/111326.htm. Acesso em 12/07/2011.

Ministério da Educação (MEC). Secretaria de Educação Continuada, Alfabetização e Diversidade (Secad). Secretaria de Educação Profissional e Tecnológica. Projeto base ProJovem Campo - Saberes da Terra: Programa Nacional de Educação de Jovens Agricultores(as) Familiares Integrada à Qualificação Social e Profissional. Brasília, 2009. Disponível em: <http://portal.mec.gov.br/dmdocuments/ projovem_projetobase2009.pdf>.

Ministério da Educação, Secretaria de Educação Continuada, Alfabetização. Cadernos Pedagógicos do Projovem Campo - Saberes da Terra (Projeto PolíticoPedagógico) / Brasília: MEC/SECAD, 2008. 
Ministério do Trabalho e Emprego. Plano Nacional de Qualificação - PNQ, 20032007. - Brasília: MTE, SPPE, 2003.

—. SEF/MEC. Parâmetros curriculares nacionais: introdução aos parâmetros curriculares nacionais. Brasília: MEC/SEF, 1997.

Congresso Nacional. Lei de Diretrizes e Bases da Educação Nacional no. 9.394. Brasília/DF, 20 de dezembro de 1996.

Ministério da Administração Federal e da Reforma do Estado (MARE). Plano Diretor da Reforma do Aparelho do Estado. Aprovado pela Câmara da Reforma do Estado, em 21 de setembro de 1995. Brasília: Presidência da República, 1995. (pp. 51-59). $\overline{1988}$.

Constituição da República Federativa do Brasil, promulgada em 5 de outubro de

BRUNO, L. Gestão da educação: onde procurar o democrático? In: OLIVEIRA, D. A. de. e ROSAR, M. de F. Política e gestão da educação. Belo Horizonte: Autêntica, 2002.

CALDART, R. S. Pedagogia do Movimento Sem Terra: escola é mais do que escola. Petrópólis: Vozes, 2002.

DELORS, J. Educação: um tesouro a descobrir. Relatório para a UNESCOda Comissão Internacional sobre Educação para o século XXI. São Paulo: Cortez; Brasília, DF: MEC: UNESCO, 2001.

GOHN, M. da G. Educação não formal e cultura popular.São Paulo: Cortez, 2001.

LIMA, A. B. O que são os Parâmetros curriculares nacionais? In: Tempo da Ciência. Volume 6, nº 12, jul/dez. 1999. P. 83-91.

LOMBARDI, J. C. Educação e Ensino na obra de Marx e Engels. Campinas: Alínea, 2011.

MARRAN, A.L. Avaliação da política de estágio curricular supervisionado: um foco na graduação em enfermagem. Relatório [Qualificação de Mestrado]. Faculdade de Educação: Universidade Federal da Grande Dourados, 2011.

MOREIRA, A. F. Parâmetros curriculares nacionais: criticas e alternativas. In: Escola S.A. - Quem ganha e quem perde no mercado educacional do neoliberalismo. Brasilia, DF: CNTE, 1996. P.128-149.

MST. Método Pedagógico. In: Cadernos do ITERRA. Ano IV, nº 9, dezembro de 2004.

PARO. V. H. Parem arem de preparar para o trabalho!!! Reflexões acerca dos efeitos do neoliberalismo sobre a gestão e o papel da escola básica. Disponível em: <www.edilsonsantos.pro.br/textos/paremdeprepararparaotrabalho.doc.>Acesso em 14 de junho de 2012. 
PENTEADO, F. dos R., TSUKUDA, J. e RUIZ, M. J. F. Os reflexos do sistema capitalista no âmbito escolar. Disponível em:

<www.estudosdotrabalho.org/anais6seminariodotrabalho>. Acesso em 14 de junho de 2012.

PISTRAK, M. Fundamentos da escola do trabalho. São Paulo: Expressão Popular, 2003.

SMITH,A. A riqueza das nações - investigação sobre sua natureza e suas causas. Volume II. São Paulo: Abril Cultural, 1983.

TAYLOR, F. W. Princípios de administração científica. São Paulo: Atlas, 1995.

UFRGS. Faculdade de Educação. Análise dos "Parâmetros curriculares nacionais". In: Escola S.A. - Quem ganha e quem perde no mercado educacional do neoliberalismo. Brasilia, DF: CNTE, 1996. P. 106-127.

\section{Notas}

\footnotetext{
${ }^{1}$ Aluna do Curso de Especialização em Educação da Universidade Federal da Grande Dourados (UFGD).

${ }^{2}$ Professor da Universidade Federal de São Carlos (UFSC).

${ }^{3}$ Professor na Universidade Federal de Uberlândia (UFU). Pesquisador da FAPEMIG e do CNPQ.

${ }^{4}$ Professora da Universidade Federal de Uberlândia (UFU).

${ }^{5}$ Para compreender tal ideia de "classificação" ver Taylor, 1995.

${ }^{6}$ BRUNO, L. Gestão da educação: onde procurar o democrático? In: OLIVEIRA, D. A. de. e ROSAR, M. de F. Política e gestão da educação. Belo Horizonte: Autêntica, 2002.

${ }^{7}$ Dentre os quais podemos destacar LIMA (1999), UFRGS (1996), MOREIRA (1996).

8 A organização dos Programas de Inclusão Social abrange outras modalidades como: Projovem Adolescente, Trabalhador e Urbano, e este, em tela, Projovem Campo - Saberes da Terra.

${ }^{9}$ Assim como Marran(2011, p.28) entendemos políticas públicas como [...] uma ou conjunto de ações promovidas pelos governantes por meio de normatizações, que num primeiro momento podem partir de discussões coletivas, mas que a posteriori se materializam seja por meio de legislações ou projetos, definidos com ou sem a participação popular, com interesse de atender a uma demanda."

${ }^{10} \mathrm{O}$ ProJovem Campo - Saberes da Terra - Saberes da Terra é um programa um programa de escolarização voltado para jovens agricultores em nível fundamental na modalidade de Educação de Jovens e Adultos (EJA),de forma integrada à capacitação profissional. O ProJovem data de 2005, implantado pelo Ministério da Educação via Secretaria de Educação Continuada, Alfabetização e Diversidade (SECAD). Sua meta inicial consiste em escolarizar 5.000 jovens agricultores de diferentes estados brasileiros: Bahia, Pernambuco, Paraíba, Maranhão, Piauí, Mato Grosso do Sul, Santa Catarina, Paraná, Minas Gerais, Pará, Tocantins e Rondônia.
} 